\title{
Efficacy and visual prognostic factors of intravitreal bevacizumab as needed for macular edema secondary to central retinal vein occlusion
}

This article was published in the following Dove Press journal:

Clinical Ophthalmology

19 November 2014

Number of times this article has been viewed

\author{
Miki Hirose \\ Wataru Matsumiya \\ Shigeru Honda \\ Makoto Nakamura \\ Department of Surgery, Division \\ of Ophthalmology, Kobe University \\ Graduate School of Medicine, \\ Chuo-ku, Kobe, Hyogo, Japan
}

Purpose: Our aim was to investigate the efficacy and prognostic factors of intraocular injections of bevacizumab as needed in patients with macular edema secondary to central retinal vein occlusion (CRVO).

Methods: This is a retrospective study including 28 eyes of 27 consecutive patients with macular edema due to CRVO and followed for at least 6 months. The mean age of the patients was 66.3 years. The patients underwent an intravitreal injection of bevacizumab $(1.25 \mathrm{mg})$ at the initial visit. Retreatments were performed when macular edema was persistent or worsened (as-needed regimen). The primary outcome measure was the mean change in best-corrected visual acuity (BCVA). The change in central retinal thickness (CRT) was evaluated as the secondary outcome. Finally, the factors useful for predicting BCVA outcome were determined.

Results: The mean number of injections was 1.8 over a period of 6 months. The mean BCVA (logarithm of minimum angle of resolution) was significantly improved at $1(-0.097), 3(-0.14)$, and 6 months $(-0.25)$ after the initial injection $(P<0.05,<0.01$, and $<0.001$, respectively). The mean CRT was also improved significantly at $1(-250.4), 3(-150.0)$, and 6 months $(-187.2)$ $(P<0.001$ each). Earlier treatment and better improvement in BCVA at 1 month after the initial treatment were the prognostic factors significantly associated with better visual outcomes at 6 months ( $P=0.047$ and 0.029 , respectively).

Conclusion: Intravitreal injection of bevacizumab as needed significantly improved visual acuity and macular edema in CRVO patients. Time before the treatment and early response to the treatment were important factors for the visual outcome.

Keywords: central retinal vein occlusion, bevacizumab, macular edema, efficacy, prognostic factor, pro re nata regimen

\section{Introduction}

Central retinal vein occlusion (CRVO) is a common vision-threatening disorder that causes sudden and severe vision loss in adults. Macular edema is one of the main causes of visual impairment in cases of CRVO. ${ }^{1-5}$ As with other retinal vascular diseases, CRVO is associated with a marked increase of intraocular vascular endothelial growth factor (VEGF). ${ }^{6-8}$ Recent randomized controlled trials demonstrated that intravitreal injections of ranibizumab or aflibercept were effective in reducing macular edema and improving the vision in patients with CRVO. ${ }^{9-11}$ However, these studies required frequent injections (6 monthly injections) to obtain the mean best-corrected visual acuity (BCVA) improved in two to three lines with early treatment diabetic retinopathy study chart at 6 months, which could be very expensive treatments. Alternatively, several studies have reported that off-label use of bevacizumab, a recombinant humanized monoclonal antibody, against all isoforms of VEGF-A, was effective in reducing macular edema
Shigeru Honda Department of Surgery, Division of Ophthalmology, Kobe University Graduate School of Medicine, 7-5-2 Kusunoki-cho, Chuo-ku, Kobe, Hyogo 650-0017, Japan

Tel +81783826048

Fax +81 783826059

Email sighonda@med.kobe-u.ac.jp 
in patients with CRVO. ${ }^{12-18}$ Because bevacizumab is much cheaper than ranibizumab or aflibercept, this drug class may have higher cost-effectiveness in treating CRVO in current clinical practice. Moreover, injections with a pro re nata (PRN) (as-needed) regimen may reduce the total number of injections compared to scheduled injections. This study was conducted to evaluate the efficacy of intravitreal injections of bevacizumab (IVB) as needed over 6 months in patients with macular edema secondary to CRVO, and we performed multivariate analysis to determine the factors associated with patients' vision after treatment.

\section{Methods}

This is a retrospective study of 28 eyes from 27 consecutive patients with CRVO-related macular edema who were treated with IVB and followed up for at least 6 months. Ten patients received other treatments before the initial IVB (sub-Tenon injection of triamcinolone acetonide for four eyes, intravitreal injection of tissue plasminogen activator for four eyes, intravenous injection of urokinase for three cases, photocoagulation for one eye, and vitrectomy for one eye).

All patients underwent full ophthalmological examinations, including fluorescein angiography (FA) and optical coherent tomography (OCT), at presentation. Four patients were diagnosed as ischemic type and the others were considered the nonischemic type. Treatment consisted of the first bevacizumab injection $(1.25 \mathrm{mg}$ ) at the initial visit, and follow-up visits were scheduled every 4 weeks thereafter. Additional injections were given when persistent or recurrent edema was detected by OCT (PRN protocol).

The demographic and clinical data analyzed were patient age and sex, systemic diseases including hypertension and diabetes mellitus, BCVA, and central retinal thickness (CRT) at presentation and at the 1-, 3-, and 6-month follow-up. The BCVA values were determined using a Landolt $\mathrm{C}$ chart and were converted to logarithm of minimum angle of resolution (logMAR) for calculation and description. The instrument used for CRT measurements was Cirrus HD-OCT model 4000 (Carl Zeiss Meditec, Dublin, CA, USA). The number of bevacizumab injections and adverse events were recorded as well. To determine the factors useful for predicting the resolution of the lesion, multivariable logistic regression analysis using a stepwise method was performed using the variables that showed some trend toward significant association $(P$-value $<0.2)$ in the univariate logistic model.

This study was approved by the Institutional Review Board at the Kobe University Graduate School of Medicine and was conducted in accordance with the Declaration of
Helsinki. Written informed consent was obtained from all subjects.

\section{Statistical analysis}

All statistical analyses were performed by MedCalc version 113 software (MedCalc Software, Ostend, Belgium). Paired $t$-test, Wilcoxon signed rank test - whichever the most appropriate - was applied to compare any two groups. $P$-values of 0.05 or less were considered statistically significant.

\section{Results}

The summary of the clinical data of the participants is shown in Table 1.

The mean duration between the onset of CRVO and the first treatment was 4.6 \pm 5.8 months (range: 0.5-27 months). The majority of patients had hypertension $(n=18,64.3 \%)$, followed by diabetes mellitus ( $n=6,21.4 \%)$. No patient in this study had diabetic retinopathy. The mean number of IVB injections was $1.8 \pm 0.9$ (range: $1-4$ ) over the 6 months of follow-up. Sixteen eyes (57.1\%) showed the recurrence of macular edema during the 6 months and the mean recurrencefree period was 2.6 \pm 0.9 months (range: $1-4$ months).

In the time-course analysis, the mean BVCA after the initial IVB was significantly improved at 1, 3, and 6 months of follow-up as compared to baseline $(-0.097,-0.14$, and $-0.25 \log$ MAR units; $P<0.05,<0.01$, and $<0.001$, respectively; Wilcoxon signed rank test) (Figure 1 and Table 2). In the time course of the mean CRT over 6 months, significant improvement was observed at 1,3 , and 6 months of follow-up compared to baseline $(-250.4 \mu \mathrm{m},-150.0 \mu \mathrm{m}$,

Table I Summary of the patients

\begin{tabular}{ll}
\hline Number of eyes (cases, N) & $28(27)$ \\
Right eye $(\mathrm{n}) \%$ & $20(71.4 \%)$ \\
Males $(\mathrm{n}) \%$ & $16(59.2 \%)$ \\
Mean age (years) ( \pm SD) & $66.3( \pm 13.5)$ \\
Duration from the onset to IVB (months) & $4.6( \pm 5.8)$ (range: $0.5-27)$ \\
Baseline BCVA (logMAR) ( \pm SD) & $0.71( \pm 0.44)$ \\
Baseline CRT ( $\mu$ m) $( \pm S D)$ & $603( \pm 183)$ \\
Previous treatment $(\mathrm{n})(\%)$ & $10(35.7 \%)$ \\
Duration from previous treatment & $5.3( \pm 4.2)($ range: $2-15)$ \\
to IVB (months) & \\
Ischemic type (NPA $\geq 10$ disk area) $(\%)$ & $4(14.3 \%)$ \\
Inner retinal fluid $(\mathrm{n})(\%)$ & $22(78.6 \%)$ \\
Outer retinal fluid $(\mathrm{n})(\%)$ & $24(85.7 \%)$ \\
Subretinal fluid $(\mathrm{n})(\%)$ & $13(46.4 \%)$ \\
Hypertension $(\mathrm{n})(\%)$ & $18(64.3 \%)$ \\
Diabetes mellitus $(\mathrm{n})(\%)$ & $6(21.4 \%)$ \\
\hline
\end{tabular}

Abbreviations: IVB, intravitreal bevacizumab; BCVA, best-corrected visual acuity; CRT, central retinal thickness; logMAR, logarithm of minimum angle of resolution; NPA, nonperfusion area; SD, standard deviation. 
A

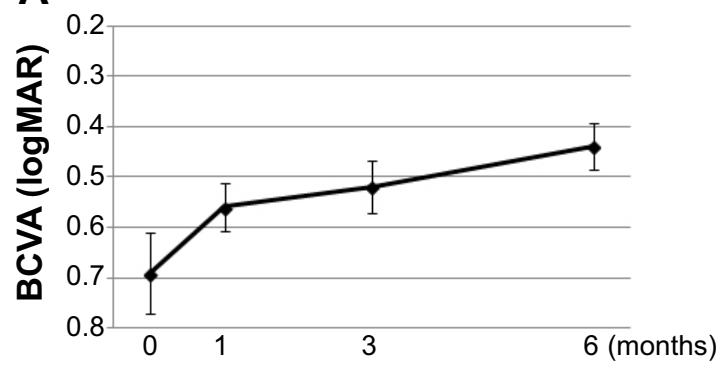

B

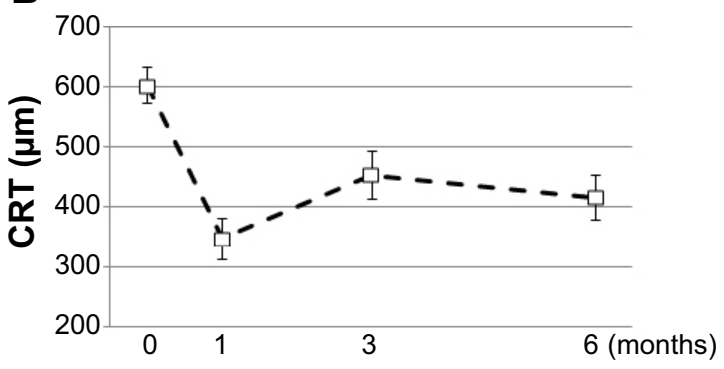

Figure I Time course of the mean BCVA and CRT from baseline in CRVO patients with IVB treatments.

Notes: Time course of (A) BCVA (logMAR) and (B) CRT.

Abbreviations: BCVA, best-corrected visual acuity; CRT, central retinal thickness; CRVO, central retinal vein occlusion; IVB, intravitreal bevacizumab; logMAR, logarithm of minimum angle of resolution.

and $-187.2 \mu \mathrm{m}, P<0.001$ each; Wilcoxon signed rank test) (Figure 1 and Table 2). The proportions of eyes in which the BCVA improved more than $0.3 \log$ MAR, changed within $0.3 \log \mathrm{MAR}$, and deteriorated more than $0.3 \log \mathrm{MAR}$ from baseline to 1, 3, and 6 months posttreatment are shown in Figure 2, which suggested an increase of eyes with better outcome over time after the initial treatment.

The results of univariate logistic regression analyses are shown in Table 3. Age, sex, pretreatment BCVA, duration from the onset to the treatment, existence of previous treatment, ischemic change, the status of macular edema, systemic hypertension, and diabetes mellitus did not show a trend toward significant association. In the multivariate logistic regression analysis, duration from the onset of disease to the initial treatment was an independent prognostic factor significantly associated with a good visual acuity $(>20 / 30)$ at 6 months (odds ratio: $0.62 ; 95 \%$ confidence interval: $0.38-0.99 ; P=0.047)$. In addition, multiple linear regression analysis revealed that the change in visual acuity at 1 month after the initial IVB was an independent prognostic factor significantly associated with the change in visual acuity at 6 months $\left(r^{2}=0.18, P=0.029\right)$.

No ocular or systemic complication was detected during the follow-up period in the current study.

\section{Discussion}

The current study has shown that IVB with a PRN regimen improved patients' vision affected by macular edema secondary to CRVO. Duration from the onset of disease to the initial treatment and the change in visual acuity at 1 month after initial treatment were independent prognostic factors significantly associated with the visual acuity at 6 months of follow-up.

Intravitreal injection of anti-VEGF agent is the first choice modality for macular edema due to CRVO in current clinical practice. ${ }^{9-15}$ Although recent studies have demonstrated the efficacy and safety of ranibizumab and aflibercept, ${ }^{9-11}$ frequent injections are required to obtain optimal outcome of the therapy, which may result in high cost of treatments. In actual clinical practice, the most frequently used anti-VEGF drug is bevacizumab. ${ }^{19}$ Epstein et al ${ }^{12}$ reported, in a prospective randomized controlled study, that IVB given every 6 weeks for 12 months significantly improved visual acuity and reduced macular edema. Moreover, some retrospective studies ${ }^{15-18}$ have reported that periodical or PRN use of IVB improved visual acuity and macular edema due to CRVO. Our results also demonstrate that IVB with a PRN regimen provides a substantial visual benefit in patients with macular edema secondary to CRVO. The patients gained mean vision of $0.25 \log$ MAR units, which is compatible with those of previous reports ${ }^{9-11}$ using fixed (monthly) injection regimen. In addition, the mean number of IVB injections in the current study (1.8 over a period of 6 months) was less than half of the monthly injections because the mean recurrence-free period was 2.6 months. Fewer injections likely have several benefits for the patients (ie, lower risk of complications, infrequent

Table 2 Changes in BCVA and CRT from baseline with IVB treatment

\begin{tabular}{lllllll}
\hline & I month & $P^{*}$ & 3 months & P* & 6 months & P* \\
\hline Change in BCVA & $-0.097 \pm 0.24$ & 0.011 & $-0.14 \pm 0.28$ & 0.0049 & $-0.25 \pm 0.25$ & 0.0001 \\
Change in CRT & $-250.4 \pm 171.3$ & $<0.0001$ & $-150.0 \pm 208.1$ & 0.0005 & $-187.2 \pm 198.4$ & 0.0002 \\
\hline
\end{tabular}

Note: *Wilcoxon signed rank test (comparison with baseline).

Abbreviations: BCVA, best-corrected visual acuity (logMAR); CRT, central retinal thickness; IVB, intravitreal bevacizumab; logMAR, logarithm of minimum angle of resolution. 


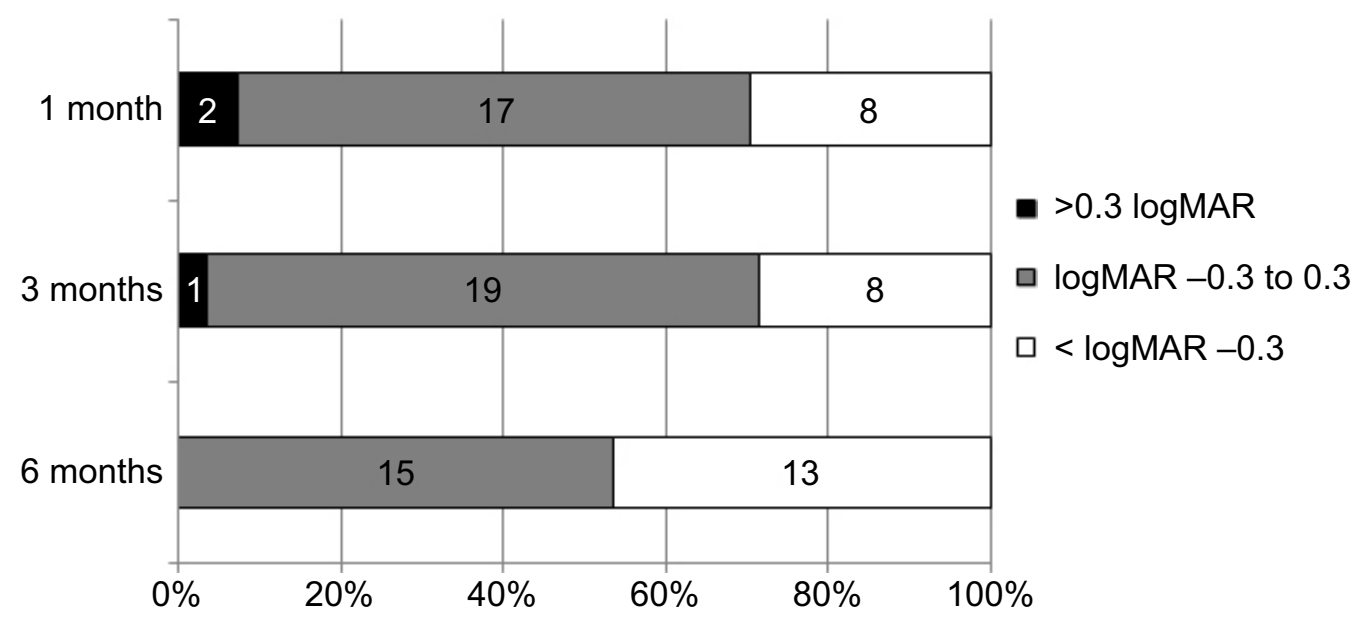

Figure 2 Chronological alterations in the distribution of visual acuity changes in CRVO patients with IVB treatments.

Notes: The proportions of eyes in which BCVA improved more than $0.3 \log M A R$, changed within $0.3 \log M A R$, and deteriorated more than 0.3 logMAR from baseline to I, 3, and 6 months posttreatment. The number of eyes is indicated in each bar.

Abbreviations: BCVA, best-corrected visual acuity; CRVO, central retinal vein occlusion; IVB, intravitreal bevacizumab; logMAR, logarithm of minimum angle of resolution.

visits to the hospital). A previous report ${ }^{20}$ described that the mean number of IVB injections with a PRN regimen was $1.8 \pm 0.8$ over 6 months in branch retinal vein occlusion cases. Our multivariable analysis revealed that the duration from the onset of disease to the initial treatment was a significant prognostic factor for visual outcome. This result was consistent with previous reports ${ }^{9-12,15}$ describing that delayed treatment with anti-VEGF agents resulted in limited visual improvement. Moreover, the current study, for the first time, demonstrated that the change in BCVA at 1 month was a significant prognostic factor associated with change in BCVA at 6 months in the CRVO patients. Therefore, earlier treatment and early response to the treatment are considered very important for the visual outcome of CRVO patients.

The limitation of the current study was that it was of a retrospective nature with a small population and a shorter follow-up period. Hence, it is not powered for safety of the treatment. The lack of control group is also a limitation of the study. Larger sample size and longer observation periods with prospective nature may lead to more precise estimates about the clinical indicators for the outcome of IVB on macular

Table 3 Factors that showed some trend toward significant association $(P$-value $<0.2)$ in the univariate logistic model

\begin{tabular}{llll}
\hline Factors & OR & $\mathbf{9 5 \%} \mathbf{C l}$ & $\boldsymbol{P}$ \\
\hline Duration from onset to treatment (months) & 0.62 & $0.38-0.99$ & 0.047 \\
Baseline BCVA (logMAR) & 0.08 & $0.004-1.5$ & 0.10 \\
Presence of prior treatment (yes =I, no =0) & 4.0 & $0.68-23.4$ & 0.12 \\
Systemic hypertension (yes =I, no =0) & 5.7 & $0.59-55.6$ & 0.13 \\
Pretreatment macular edema (yes =I, no =0) & 0.29 & $0.045-1.9$ & 0.20 \\
\hline
\end{tabular}

Abbreviations: $\mathrm{OR}$, odds ratio; $\mathrm{Cl}$, confidence interval; $\mathrm{BCVA}$, best-corrected visual acuity; logMAR, logarithm of minimum angle of resolution. edema secondary to CRVO. However, our results suggest that some clinical information might be useful to predict the visual outcome of CRVO patients.

\section{Conclusion}

IVB with a PRN regimen significantly reduced macular edema and improved visual acuity of CRVO patients. Patients receiving earlier treatment had greater chance to obtain good visual outcome. The change in BCVA at 1 month was positively correlated with the change in BCVA at 6 months of follow-up.

\section{Disclosure}

The authors report no conflicts of interest in this work.

\section{References}

1. Natural history and clinical management of central retinal vein occlusion. The Central Vein Occlusion Study Group. Arch Ophthalmol. 1997;115: 486-491.

2. Mitchell P, Smith W, Chang A. Prevalence and associations of retinal vein occlusion in Australia: the Blue Mountains Eye Study. Arch Ophthalmol. 1996;114:1243-1247.

3. Klein R, Klein BE, Moss SE, Meuer SM. The epidemiology of retinal vein occlusion: the Beaver Dam Eye Study. Trans Am Ophthalmol Soc. 2000;98:133-141.

4. Rogers S, McIntosh RL, Cheung N, et al; International Eye Disease Consortium. The prevalence of retinal vein occlusion: pooled data from population studies from the United States, Europe, Asia, and Australia. Ophthalmology. 2010;117:313-319.

5. McIntosh RL, Rogers SL, Lim L, et al. Natural history of central retinal vein occlusion: an evidence-based systematic review. Ophthalmology. 2010;117:1113-1123.

6. Aiello LP, Avery RL, Arrigg PG, et al. Vascular endothelial growth factor in ocular fluid of patients with diabetic retinopathy and other retinal disorders. N Engl J Med. 1994;331:1480-1487.

7. Park SP, Ahn JK, Mun GH. Aqueous vascular endothelial growth factor levels are associated with serous macular detachment secondary to branch retinal vein occlusion. Retina (Philadelphia, PA). 2010;30:281-286. 
8. Noma H, Funatsu H, Mimura T, Eguchi S, Shimada K. Role of soluble vascular endothelial growth factor receptor-2 in macular oedema with central retinal vein occlusion. Br J Ophthalmol. 2011;95:788-792.

9. Brown DM, Campochiaro PA, Singh RP, et al; CRUISE Investigators. Ranibizumab for macular edema following central retinal vein occlusion: six-month primary end point results of a phase III study. Ophthalmology. 2010;117:1124.e1-e1133.e1.

10. Holz FG, Roider J, Ogura Y, et al. VEGF Trap-Eye for macular oedema secondary to central retinal vein occlusion: 6-month results of the phase III GALILEO study. Br J Ophthalmol. 2013;97:278-284.

11. Boyer D, Heier J, Brown DM, et al. Vascular endothelial growth factor Trap-Eye for macular edema secondary to central retinal vein occlusion: six-month results of the phase 3 COPERNICUS study. Ophthalmology. 2012;119:1024-1032.

12. Epstein DL, Algvere PV, von Wendt G, Seregard S, Kvanta A. Benefit from bevacizumab for macular edema in central retinal vein occlusion: twelve-month results of a prospective, randomized study. Ophthalmology. 2012;119:2587-2591.

13. Epstein DL, Algvere PV, von Wendt G, Seregard S, Kvanta A. Bevacizumab for macular edema in central retinal vein occlusion: a prospective, randomized, double-masked clinical study. Ophthalmology. 2012;119:1184-1189.

14. Preti RC, Ramirez LM, Pimentel SL, et al. Effect of a single intravitreal bevacizumab injection on contrast sensitivity and macular thickness in eyes with macular edema from central retinal vein occlusion: a prospective, nonrandomized, three-month follow-up study. Ophthalmic Res. 2014;51:140-145.
15. Pikkel J, Chassid O, Busool Y, Srour W, Sharabi-Nov A, Beiran I. Bevacizumab for CRVO associated CME: effect of timing and frequency of injections on final visual outcome. J Ophthalmol. 2013;2013: 974670 .

16. Axer-Siegel R, Dotan A, Mimouni K, Bor E, Weinberger D, Bourla DH. Intravitreous bevacizumab treatment for macular edema due to central retinal vein occlusion. Curr Eye Res. 2012;37:818-822.

17. DeCroos FC, Ehlers JP, Stinnett S, Fekrat S. Intravitreal bevacizumab for macular edema due to central retinal vein occlusion: perfused vs ischemic and early vs late treatment. Curr Eye Res. 2011;36: 1164-1170.

18. Iturralde D, Spaide RF, Meyerle CB, et al. Intravitreal bevacizumab (Avastin) treatment of macular edema in central retinal vein occlusion: a short-term study. Retina. 2006;26:279-284.

19. Martin DF, Maguire MG, Ying GS, et al. Ranibizumab and bevacizumab for neovascular age-related macular degeneration. $N$ Engl J Med. 2011;364:1897-1908.

20. Ahn SJ, Ahn J, Woo SJ, Park KH. Initial dose of three monthly intravitreal injections versus PRN intravitreal injections of bevacizumab for macular edema secondary to branch retinal vein occlusion. Biomed Res Int. 2013;2013:209735.
Clinical Ophthalmology

\section{Publish your work in this journal}

Clinical Ophthalmology is an international, peer-reviewed journa covering all subspecialties within ophthalmology. Key topics include: Optometry; Visual science; Pharmacology and drug therapy in eye diseases; Basic Sciences; Primary and Secondary eye care; Patien Safety and Quality of Care Improvements. This journal is indexed on

Submit your manuscript here: http://www.dovepress.com/clinical-ophthalmology-journal

\section{Dovepress}

PubMed Central and CAS, and is the official journal of The Society of Clinical Ophthalmology (SCO). The manuscript management system is completely online and includes a very quick and fair peer-review system, which is all easy to use. Visit http://www.dovepress.com/ testimonials.php to read real quotes from published authors. 